\title{
Available Bandwidth-aware Routing in Urban Vehicular Ad-hoc Networks
}

\author{
Carolina Tripp Barba*, Ahmad Mohamad Mezher*, Mónica Aguilar Igartua*, Isabelle Guérin-Lassous ${ }^{\dagger}$ and \\ Cheikh Sarr ${ }^{\ddagger}$ \\ * Departament d'Enginyeria Telemàtica, Universitat Politècnica de Catalunya (UPC), Barcelona, Spain \\ \{ctripp, ahmad.mezher, monica.aguilar\}@entel.upc.edu \\ †Université Claude Bernard, Lyon 1, LIP (UMR ENS Lyon - INRIA - CNRS - UCBL), Lyon, France \\ isabelle.guerin-lassous@ens-lyon.fr \\ ${ }^{\ddagger}$ Université de Thies, UFR Sciences et Technologies, Thies, Senegal \\ csarr1979@hotmail.com
}

\begin{abstract}
Vehicular communication for intelligent transportation systems will provide safety, comfort for passengers, and more efficient travels. This type of network has the advantage to warn drivers of any event occurred in the road ahead, such as traffic jam, accidents or bad weather. This way, the number of traffic accidents may decrease and many lives could be saved. Moreover, a better selection of non-congested roads will help to reduce pollution. Some other interesting services, such as downloading of multimedia services, would be possible and available through infrastructure along the roadside. Providing multimedia services over VANETs may require a QoS-aware routing protocol that often need to estimate available resources. In this paper, we study the performance, in realistic VANET urban scenarios, of an extension of AODV that includes the available bandwidth estimator ABE [1]. AODV-ABE establishes forwarding paths that satisfy the bandwidth required by the applications. The results, obtained on the NCTUns simulator [2], show that AODVABE could be used in urban-VANETs where vehicles' speed is moderate.
\end{abstract}

Index Terms-Intelligent Transportation Systems, Vehicular Ad hoc Networks, Available Bandwidth Estimator, Performance evaluation.

\section{INTRODUCTION}

A vehicular Ad-hoc Network (VANET) [3] [4] is a specific type of mobile ad-hoc network (MANET) that provides vehicle-to-vehicle and vehicle-to-roadside wireless communications. VANETs have some specific characteristics compared to MANETs:

- Vehicles move at higher speeds and consequently lifetimes of routing links are shorter; thus, routing protocols must cope with the rapid changes in the network topology.

- The mobility of vehicles is restricted by the road layout, the other vehicles' movements and the traffic rules.

- VANETs are also affected by factors such as weather, road conditions, accidents and traffic jams.

VANET systems will enable applications in three primary directions: safety, traffic efficiency and infotainment. The first two categories are the main goals of vehicular technology. The third category influences on newly coined and existing services that naturally combine VANET and Intelligent Transportation Systems (ITS) [5] contexts, which can act as a market force.
Infotainment implies the use of multimedia services (e.g. video streaming) that require network resources to run correctly.

In this work, our main motivation is to design a routing protocol for VANETs able to establish forwarding paths that fulfill bandwidth requirements. To this end, we study the possibility to use, in realistic VANET urban scenarios, the available bandwidth estimator (ABE) that was proposed and evaluated for IEEE 802.11-based MANETs in [1]. We have implemented in NCTUns [2] an extension of AODV [6] that includes the $\mathrm{ABE}$ estimation. $\mathrm{ABE}$ is used to assist the AODV routing protocol so that the established forwarding path satisfies the bandwidth required by the application. This extension is called AODV-ABE hereafter. Knowing that available bandwidth estimations are often weak regards to mobility, our simulation results show that AODV-ABE could be used in urban-VANETs where vehicles' speed is moderate. Besides, our framework includes a warning service that aims at avoiding road accidents.

The rest of the paper is organized as follows. Section II gives a state-of-the-art of some recent relevant works of QoSaware proposals for VANETs. Section III summarizes the ABE estimation. Section IV describes the warning service we propose to prevent road accidents. Section V shows a performance evaluation of the AODV-ABE scheme over VANETs. Finally, section VI gives conclusion and future work.

\section{StATE-OF-THE-ART}

Safety, comfort driving and infotainment applications for passengers are some of the main services proposed for VANETs. Some services are critical, such as collision warning; other services need bandwidth, such as video-streaming services. QoS (Quality of Service) provisioning is a challenge in VANETs due to their special features which result in frequent routing path disruptions.

In order to offer services over wireless ad-hoc networks with good performance, QoS mechanisms often require an estimation of available resources. In multihop ad-hoc networks, the estimation of the available bandwidth is a difficult task. Several proposals [1] [7] [8] have been presented to compute the available bandwidth on IEEE 802.11 wireless links and 
most of them have been evaluated in MANETs. For instance, ABE [1] combines channel monitoring to estimate each node's medium occupancy including distant emissions, probabilistic combination of these values to account for synchronization between nodes, estimation of the collision probability between each couple of nodes, and variable overhead's impact estimation. This mechanism only requires one hop information communication and may be applied without generating a too high additional overhead. RABE [7] (Retransmissionbased Available Bandwidth Estimation) also considers in its estimation the bandwidth wasted by extra waiting time and medium occupancy due to retransmission. This estimation requires to compute the collision probability and the mean number of retransmission attempts. IAB [8] takes into account the common medium occupation periods between the two end nodes of each link and the independent occupations periods. They are computed thanks to the sensing busy state during which one end node senses the medium busy while its neighbor senses the medium idle. This computation assumes a uniform distribution of nodes in the network.

Current routing protocols in VANETs have difficulties to provide QoS. A QoS-aware routing protocol should guarantee satisfactorily a certain level of performance. This is often achieved through resource reservation and dedicated infrastructure. However, the dynamic and infrastructureless nature of VANETs makes it difficult to do resource reservation. Some actions to improve the performance in vehicular routing have been proposed, e.g. algorithms to estimate the time during which a route will remain connected [9]. The work in [10] presents a routing protocol to improve QoS in VANETs in terms of delay, response time and throughput. This scheme disseminates packets among the links that have longer expiration time. The routing selection and maintenance are based on the mobility of vehicles. A routing algorithm for achieving optimal QoS for highly dynamic VANETs is proposed in [11]. The proposal identifies optimal paths using the idea of next hop selection, considering parameters such as delay, packet loss and bandwidth.

Regarding routing protocols, the advantage of AODV [6] is its simplicity and widespread use. The main drawback is that AODV needs end-to-end paths for data forwarding, which is difficult to handle because in VANETs end-to-end paths break often due to high speeds of vehicles. Other routing protocols use strategies like greedy forwarding and geographical routing [12] [13], but at the cost of greater complexity and increased delay. Nonetheless, for some multimedia applications that require a minimum bandwidth and short delay AODV can perform well. In this paper we are considering smart city services where vehicles need to find quickly the closest Access Point (e.g. set in some intelligent traffic lights) for instance to send a short video clip of an accident to the ambulance unit, a picture reporting a traffic infraction or to retrieve a short video clip of the traffic conditions ahead. In this kind of applications, it is not necessary to establish long paths that last long, the communication must be quick and a minimum bandwidth should be provided.
Our proposal is similar to the works [9], [10] and [11], in the sense that it uses AODV as the basic operation to find routes and it includes algorithms to improve the performance of QoS parameters. Nevertheless, none of these works includes a realtime analytical scheme based on very few measurements to estimate the bandwidth, which is what we use in our proposal. The goal in this work is to evaluate the benefits of the AODVABE analytical tool to estimate the available bandwidth over a VANET urban scenario.

\section{ABE: Available Bandwidth Estimation}

In this section we summarize the main features of $\mathrm{ABE}$ (Available Bandwidth Estimation) proposed in [1] to estimate the available bandwidth in IEEE 802.11-based ad hoc networks. IEEE 802.11 is the standard adopted in VANETs [3] [4]. In particular, the IEEE $802.11 \mathrm{p}$ extension includes specific features for the physical layer (e.g. codification, frequency) to cope with the issues of high mobility nodes. The MAC layer in IEEE $802.11 \mathrm{p}$ is exactly the same as in IEEE 802.11 . As ABE bases its estimation on the IEEE 802.11 MAC principle, we only consider IEEE 802.11 hereafter. For a full description of $\mathrm{ABE}$, the interested reader can refer to [1].

\section{A. Idle periods synchronization}

In $\mathrm{ABE}$, each node estimates its idle time period by sensing the medium. The available bandwidth estimation of a wireless link in $\mathrm{ABE}$ uses the idle time periods of the emitter and the receiver of the link. However, for a communication to take place, emitter and receiver must be both idle. As there is no reason that emitters and receivers are always idle at the same time, ABE includes, in its estimation, the probability that two end nodes of a link be both idle at the same time. To this end, a uniform random distribution of the medium occupancy over an observation period is assumed. The basic analytical expression to estimate the available expected bandwidth $E\left(b_{(s, r)}\right)$ in the wireless link formed by nodes $s$ and $r$ considering the overlapped synchronization periods is:

$$
E\left(b_{(s, r)}\right)=T_{s} \cdot T_{r} \cdot C
$$

where $T_{s}$ is the idle time period at the sender side, $T_{r}$ is the idle time period at the receiver side and $C$ is the maximum medium capacity.

\section{B. Collision and backoff mechanism}

As the estimation of the idle periods synchronization is only probabilistic, collisions can still arise. This happens when a packet is emitted while the medium is not idle at the receiver's side. Such a collision triggers the binary exponential backoff mechanism. Collisions and a backoff increase impact the available bandwidth. ABE computes the collision probability from Hello messages often used in routing protocols. The packet collision probability $p_{m}$ for packets of $m$ bits is derived from the collision probability of Hello messages, $p_{\text {hello }}$, in the following way:

$$
p_{m}=f_{m} \cdot p_{\text {hello }}
$$


where $f_{m}$ is a Lagrange interpolating polynomial obtained from simulation. The additional overhead introduced by the binary exponential backoff mechanism is computed as:

$$
K=\frac{D I F S+\overline{\text { backoff }}}{T_{m}}
$$

where $T_{m}$ (in sec) is the time separating the emission of two consecutive frames, DIFS [14] is a fixed interval and backoff is the number of backoff slots decremented on average for a single frame.

Finally, by merging these different mechanisms that impact the available bandwidth, ABE estimates the available bandwidth on a wireless link as follows:

$$
E_{\text {final }}\left(b_{(s, r)}\right)=(1-K) \cdot\left(1-p_{m}\right) \cdot T_{s} \cdot T_{r} \cdot C
$$

\section{C. $A O D V-A B E$}

$\mathrm{AODV}-\mathrm{ABE}$ is a modification of the AODV routing protocol that includes $\mathrm{ABE}$ in its operation to estimate the available bandwidth on wireless links. Nodes periodically update their available bandwidth using the ABE mechanism with Eq. (4). When a new source wants to send a packet to a destination, AODV-ABE floods a route request message (RREQ) to that destination by including the required bandwidth in the RREQ. Each intermediate node that receives the RREQ checks if there is enough bandwidth on the link from which it receives the RREQ. If this is the case, the RREQ is forwarded; conversely, the required bandwidth can not be satisfied and the RREQ is simple discarded. This allows us to establish a forwarding path that satisfies the required bandwidth.

\section{WARNING SERVICES}

We have implemented a warning service to prevent accidents by alerting drivers about accidents and dangerous road conditions. Vehicles flood their near zone in the VANET with short warning messages if the sensors in the vehicle detect one of the situations depicted in Table I. Warning messages are flooded car-by-car using AODV-ABE, although here AODVABE will not make any difference compared to AODV, since the warning messages are very small and their transmissions require a very low bandwidth.

A 4-bit field in the warning messages codes traffic density ( 2 bits) and weather information ( 2 bits). The time to live (TTL) of these messages limit the range of the alert to the neighborhood of the vehicles. Vehicles that receive such a message will reduce their speed according to Table 1. For instance, in a very congested road segment with rain condition, warning messages inform vehicles to reduce their speed to $40 \%$ of the initial driver speed. The driver's assistant device in the vehicles will make the vehicle brake accordingly.

\section{Simulation Results}

This section presents some representative simulation results of the performance evaluation of the AODV-ABE routing protocol in VANET urban scenarios and compares AODV$\mathrm{ABE}$ to AODV. The general simulation settings are given in
TABLE I

\begin{tabular}{|c|c|c|}
\hline $\begin{array}{l}\text { Traffic density } \\
\text { (2-bit) }\end{array}$ & $\begin{array}{l}\text { Weather } \\
\text { (2-bit) }\end{array}$ & $\begin{array}{c}\text { Warning message: } \\
\text { reduce speed }\end{array}$ \\
\hline \multirow{2}{*}{ Free road segment } & Sun & $\mathrm{U}$ \\
\hline & Rain & $85 \% \cdot U$ \\
\hline \multirow{2}{*}{$\infty \quad \infty \quad \infty$} & Storm & $65 \% \cdot U$ \\
\hline & Ice & $40 \% \cdot U$ \\
\hline \multirow{2}{*}{ Semi-congested road segment } & Sun & $75 \% \cdot U$ \\
\hline & Rain & $50 \% \cdot U$ \\
\hline \multirow{2}{*}{ 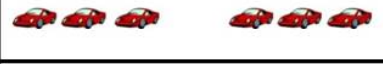 } & Storm & $25 \% \cdot U$ \\
\hline & Ice & $10 \% \cdot U$ \\
\hline \multirow{4}{*}{ Very congested road segment } & Sun & $50 \% \cdot U$ \\
\hline & Rain & $40 \% \cdot U$ \\
\hline & Storm & $30 \% \cdot U$ \\
\hline & Ice & $10 \% \cdot U$ \\
\hline \multirow{4}{*}{ Accident } & Sun & 0 \\
\hline & Rain & 0 \\
\hline & Storm & 0 \\
\hline & Ice & 0 \\
\hline
\end{tabular}

CODE OF TRAFFIC AND WEATHER SITUATIONS

$U$ : Initial driver speed

TABLE II

SIMULATION SETTINGS

\begin{tabular}{|c|c|}
\hline Parameter & Value \\
\hline Medium capacity & $2 \mathrm{Mbps}$ \\
\hline Packet size & $1000 \mathrm{bytes}$ \\
\hline Transmission range & $250 \mathrm{~m}$ \\
\hline Carrier sense & $550 \mathrm{~m}$ \\
\hline Simulation time & $200 \mathrm{sec}$ \\
\hline MAC specification & IEEE $802.11 \mathrm{~b}$ \\
\hline Area & $700 \times 700 \mathrm{~m}^{2}$ \\
\hline Maximum speed & $18 \mathrm{~km} / \mathrm{h}(5 \mathrm{~m} / \mathrm{sec})$ \\
\hline Number of nodes & 30 \\
\hline TTL (warning messages) & 5 \\
\hline Propagation channel model & Two Ray Ground Model \\
\hline Mobility model & Manhattan-Citymob \\
\hline Routing protocol & AODV, AODV-ABE \\
\hline
\end{tabular}

Table II. The propagation model employed in our simulation is the Two Ray Ground Model. IEEE 802.11p is not implemented yet in NCTUns. However, as said previously, we can use IEEE 802.11 since both have the same MAC operation. The only difference is that IEEE $802.11 \mathrm{p}$ improves the physical layer for high speeds, so we could expect even better results with IEEE 802.11p. We test two urban scenarios: a scenario where vehicles remain static to show the potential benefits of AODV$\mathrm{ABE}$ in the most favorable scenario compared to AODV; a scenario where vehicles move according to the mobility model generator Citymob [15]. This mobility model generator allows us to create realistic urban mobility scenarios where cars follow streets and respect traffic signals. We have carried out several simulations for each scenario obtaining similar results. Due to space limitations, we show here only a group of results. The urban scenarios have 30 nodes randomly positioned in the streets. There are 7 streets per side, $100 \mathrm{~m}$. each, and there are traffic lights at each intersection. At intersections, cars randomly can turn right, left or continue in the same direction.

Three CBR flows are sent, with source and destination randomly selected. Each flow is composed of 1000-byte packets with a data rate of $800 \mathrm{kbps}$ using a $2 \mathrm{Mbps}$ medium capacity. We use CBR flows to have identical scenarios between AODV- 


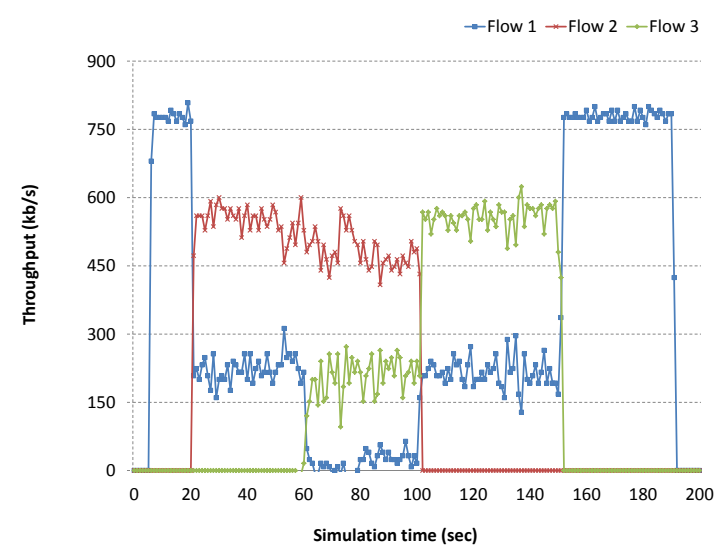

Fig. 1. Throughput with AODV. Static nodes.

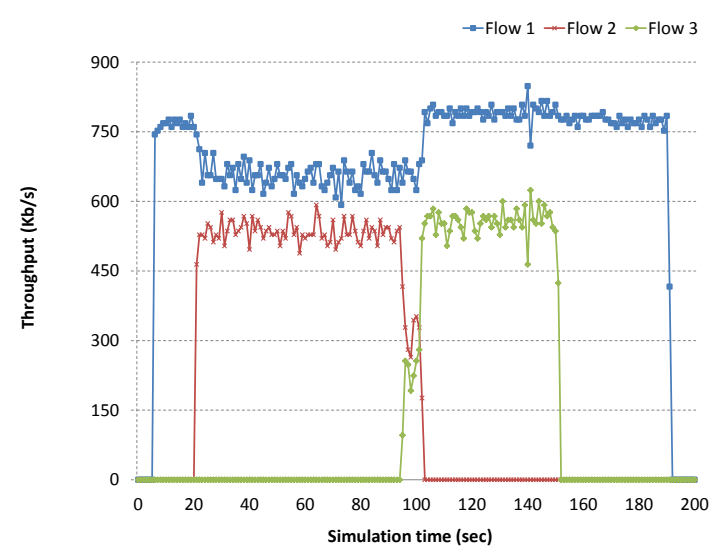

Fig. 2. Throughput with AODV-ABE. Static nodes.

$\mathrm{ABE}$ and AODV and to show clearly the bandwidth obtained using these solutions (the comparison would be more difficult in case of VBR or TCP flows). Flow 1 starts at $5 \mathrm{sec}$. and ends at $190 \mathrm{sec}$; flow 2 starts at $20 \mathrm{sec}$. and ends at $100 \mathrm{sec}$. and flow 3 starts at $60 \mathrm{sec}$. and ends at $150 \mathrm{sec}$.

First, we analyze the performance in the static scenario. Fig. 1 shows the throughput of the three flows when AODV is used. At 5 sec., flow 1 starts its transmission and obtains its target throughput (i.e. $800 \mathrm{kbps}$ ). At 20 sec., flow 2 (which also requires $800 \mathrm{kbps}$ ) starts, affecting flow 1 which gets a lower throughput (decreases to $200 \mathrm{kbps}$ ). At $60 \mathrm{sec}$., flow 3 starts and the network gets so congested that the three flows obtain a throughput much lower than required $(50,500$ and $200 \mathrm{kbps}$ respectively). At $100 \mathrm{sec}$. flow 2 ends, and flows 1 and 3 start to achieve a better throughput (200 and 600 $\mathrm{kbps}$, respectively). Only when flow 3 ends (150 sec.), flow 1 gets again the target throughput. In this case, the lack of admission control mechanism makes it impossible to guarantee a minimum bandwidth per flow.

Fig. 2 shows the throughput when we include $A B E$ in AODV. We can see that up to around $100 \mathrm{sec}$., only two flows are admitted, although flow 3 tried to start at $60 \mathrm{sec}$.

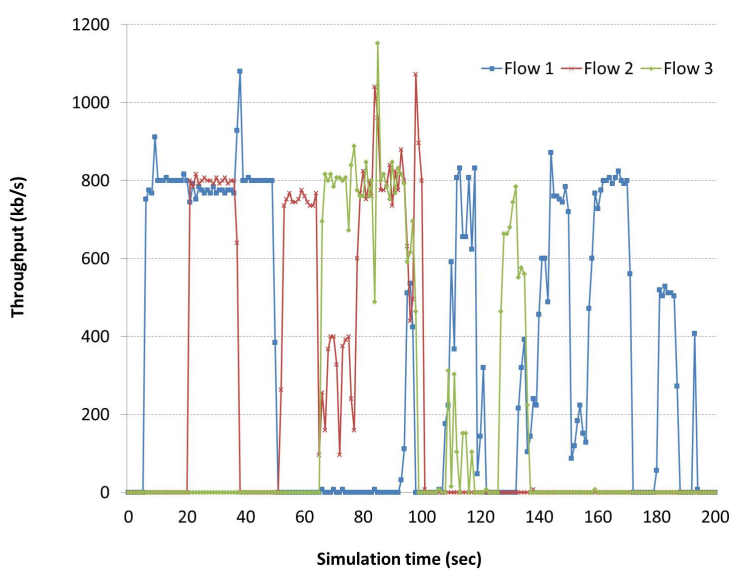

Fig. 3. Throughput with AODV. Mobile nodes $(5 \mathrm{~m} / \mathrm{sec})$.

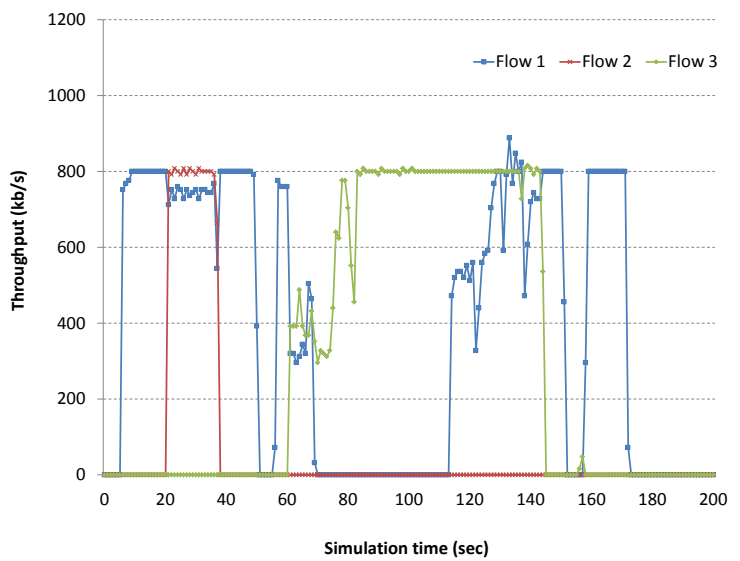

Fig. 4. Throughput with AODV-ABE. Mobile nodes $(5 \mathrm{~m} / \mathrm{sec})$.

This is due to the connection access control of $\mathrm{ABE}$ that does not allow another communication to start transmitting if there are not enough resources. It is only when one of the active flow ends (flow 2 at $100 \mathrm{sec}$.) that flow 3 can start its communication. As expected, AODV-ABE only accepts a new flow if the medium has enough capacity to offer the required throughput. AODV-ABE shows more stable throughputs and establishes forwarding paths that are able to guarantee the required bandwidth, so it is suitable for bandwidth demanding services such as video-streaming.

Let us now see the impact of mobility. In the second scenario we evaluate a VANET in the same previous urban area, but now using the Manhattan mobility model generated in Citymob [15], with a maximum vehicles' speed of $18 \mathrm{~km} / \mathrm{h}$ $(5 \mathrm{~m} / \mathrm{sec}$.). This scenario has the same flows than in the static case. Fig. 3 shows the throughput using AODV. We can see that, at the beginning (up to $50 \mathrm{sec}$.), two flows are present but due to the vehicles' movement, flow 1 suffers a breakage and does not find a new route until $100 \mathrm{sec}$. In addition, after the $70 \mathrm{sec}$. the three flows are quite unstable due to mobility, since nodes (vehicles) follow streets, respect signals and move quickly, producing frequent link breakages. 
TABLE III

DRIVER'S REACTION TIME AND DISTANCE TRAVELLED

\begin{tabular}{|c|l|l|}
\hline & $\begin{array}{l}\text { Use of } \\
\text { warning } \\
\text { messages }\end{array}$ & $\begin{array}{l}\text { Non use of } \\
\text { warning } \\
\text { messages }\end{array}$ \\
\hline Driver's reaction time & $0,084 \mathrm{~s}$ & $1 \mathrm{~s}$ \\
\hline Distance travelled till reaction & $0,93 \mathrm{~m}$ & $11,11 \mathrm{~m}$ \\
\hline Braking period of time & $1,355 \mathrm{~s}$ & $1,355 \mathrm{~s}$ \\
\hline Distance travelled during braking & $7,52 \mathrm{~m}$ & $7,52 \mathrm{~m}$ \\
\hline Total distance travelled & $8,45 \mathrm{~m}$ & $18,63 \mathrm{~m}$ \\
\hline
\end{tabular}

Fig. 4 shows the performance of AODV-ABE in the second scenario. Flow 1 presents the same link breakage at second 50 . However, once it is recovered (around $110 \mathrm{sec}$.), its throughput is more stable. The same happens with flow 3 between $70 \mathrm{sec}$. and $150 \mathrm{sec}$. which represents the end of this communication. In this case, flow 2 only obtained access between 20 and $40 \mathrm{sec}$. This is due to the ABE admission control: since the medium is full with flows 3 and 1 , it is not possible for flow 2 to recover with the required throughput and it cannot reestablish its connection. Again, we can see that AODV-ABE improves notably the performance compared to AODV. We see also that AODV-ABE suffers the same mobility problems as AODV, since it does not tackle the mobility issue but the bandwidth management. However, we see that under the moderate mobility of urban scenarios, AODV-ABE performs remarkably better than AODV.

To evaluate the benefits of the warning service proposed in Sec. IV, we have used an urban scenario to show how the vehicles react under different traffic and weather conditions. In this simulation, a car accident in a zone of the city is simulated. This scenario recreates a Manhattan $2 \times 2$ blocks scenario with 5 vehicles. When the simulation starts, the traffic condition is "free segment" and the weather condition "sun". 30 seconds after, the accident occurs so the traffic condition changes to "accident" and the vehicles in the near zone reduce their velocity until they stop. The objective of this simulation is to evaluate if the use of warning messages reduce the driver's reaction time after accidents. According to the Dirección General de Tráfico (DGT) [16], who is in charge of the transportation policy in Spain, the average reaction time of a driver is $1 \mathrm{sec}$, so a car $(v=40 \mathrm{~km} / \mathrm{h})$ before starting to brake travels $11,11 \mathrm{~m}$. Using our framework the driver's reaction time was $0,084 \mathrm{sec}$. Table III shows the time and distances that a vehicle, in average, travels with and without the use of our warning service. We consider negligible the reaction time of the sensor that detects the accident. In this case, it can be appreciated that the safety distance from the car to the obstacle has been reduced to approximately 55\% from $18,63 \mathrm{~m}$ without the use of ITLs to $8,45 \mathrm{~m}$ using them, which notably increases road safety.

\section{CONClusions ANd Future Work}

In this work, we have studied the possibility to use, in realistic VANET urban scenarios, the available bandwidth estimator (ABE) in the AODV routing protocol (called AODV$\mathrm{ABE}$ ), so that the established forwarding path satisfies the bandwidth required by the application. We have implemented
AODV-ABE in NCTUns and tested the performance of AODVABE over urban VANETs by using the realistic traffic model generator Citymob [15]. Simulation results show that, with AODV-ABE, flows can achieve the required throughput under a moderate mobility. Under high mobility, it is more difficult to establish the forwarding paths with a given throughput. In this case, AODV-ABE needs specific mechanisms to take mobility into account. As a future work, we plan to study such mechanisms to add into AODV-ABE trying to make the solution more robust to high mobility or to include this tool in a geographic routing protocol for VANETs.

\section{ACKNOWLEDGEMENTS}

This work has been partially funded by the Spanish Ministry of Science and Education under the project CICYT CONSEQUENCE (TEC2010-20572-C02-02); by the Comissionat per a Universitats i Recerca del DIUE from the Generalitat de Catalunya and the Social European Budget (Fons Social Europeu) with the grant FI-AGAUR; and by the Autonomous University of Sinaloa, Mexico.

\section{REFERENCES}

[1] Sarr, C., Chauder, G., Chelius, G., Guérin-Lassous, I., "Bandwidth Estimation for IEEE 802.11-Based Ad Hoc Networks", IEEE Transac. on Mobile Computing, Vol. 7, No. 10, pp. 1228-1241, 2008.

[2] The NCTUns 6.0 Network Simulator and Emulator. Available at http://NSL.csie.nctu.edu.tw/nctuns.html.

[3] Hartenstein, H., Laberteaux, K., "VANET Vehicular Applications and Inter-Networking Technologies (Intellig. Transp. System)", Wiley, 2010.

[4] Olariu, S., Weigle, M., "Vehicular Networks from Theory to Practice", Norfolk, Virginia, USA, Chapman and Hall, 2009.

[5] Dimitrakopoulos, G., Demestichas, P., "Intelligent Transportation System. System Based on Cognitive Networking and Management Functionally", IEEE Vehicular Technology Magazine, pp. 77-84, 2010.

[6] Perkins, C.E., Belding-Royer, E. M., Das, S.R., "Ad hoc On-Demand distance Vector routing", IEEE Personal Commu., pp. 16-28, 2001.

[7] Nguyen, V. M., Guérin-Lassous, I., Moraru, V., Sarr, C., "Retransmission-based Available Bandwidth Estimation in IEEE 802.11-based Multihop Wireless Networks", 14th ACM Int. Conf. on Modeling, Analysis and Simul. of Wireless and Mobile Systems (MSWiM), 2011.

[8] H. Zhao, E. García-Palacios, J. Wei. And Y. Xi., "Accurate available bandwidth estimation in IEEE 802-based ad hoc networks", Elsevier Computer Communications, Vol. 32, Issue 6, pp. 1050-57, 2009.

[9] Mo, Z., Zhu, H., Makki, K., Pissinou, N., "MURU: A Multi-Hop Routing Protocol for Urban Vehicular Ad Hoc Networks", 3rd Annual Int. Conf. on Mobile and Ubiquitous Systems: Networking \& Services, pp. 1-8, 2006

[10] Gongjun Y., Rawat, D.B., Bista, B.B., "Provisioning Vehicular Ad Hoc Networks with QoS", Int. Conf. on Broadband, Wireless Computing, Communic. and Applications (BWCCA), pp. 102-107, 2010.

[11] Subramaniam, P. R., Thangavelu, A., Venugopal, C., "QoS for highly dynamic Vehicular ad hoc network optimality", 11th International Conference on ITS Telecommunications (ITST), pp. 405-411, 2011.

[12] Brad K., Kung, H.T., "GPSR: Greedy Perimeter Stateless Routing for wireless Networks", MobiCom 2000.

[13] Zhongyi, L., Tong, Z., Wei, Y., Xiaoming, L., "GOSR: Geographical Opportunistic Source Routing for VANETs", ACM SIGMOBILE Mobile Computing and Communications, Vol. 13, Issue 1, January 2009.

[14] IEEE 802.11 Standard, "Part 11: Wireless LAN Medium Access Control (MAC) and Physical Layer (PHY) Specifications", 2007. http://standards.ieee.org/getieee802/download/802.11-2007.pdf.

[15] Martínez, F. J., Cano, J.C., Calafate, C. T., Manzoni, P., "CityMob: a mobility model pattern generator for VANETs", Proceedings IEEE communications society, ICC'08 Workshop, pp. 370-374, 2008.

[16] Dirección General de Tráfico "Revista Tráfico 192", December 2011, http://www.dgt.es/revista/num192/pages/infografias.html 